\title{
Biological Control of Take-All and Growth Promotion in Wheat by Pseudomonas chlororaphis YB-10
}

\author{
Wen Xu ${ }^{1,2}$, Lingling $X u^{3}{ }^{3}$, Xiaoxu Deng ${ }^{1,2}$, Paul H. Goodwin ${ }^{4}$, Mingcong Xia ${ }^{1,2}$, Jie Zhang ${ }^{1,2}$, Qi Wang ${ }^{5}$, \\ Runhong Sun ${ }^{1,2}$, Yamei Pan ${ }^{1,2}$, Chao Wu ${ }^{1,2}$ and Lirong Yang ${ }^{1,2, *}$ \\ 1 Institute of Plant Protection Research, Henan Academy of Agricultural Sciences, Zhengzhou 450002, China; \\ xuwen@hnagri.org.cn (W.X.); ddengxiaoxu@hnagri.org.cn (X.D.); xiamingcong@hnagri.org.cn (M.X.); \\ zhangjie@hnagri.org.cn (J.Z.); sunrunhong@hnagri.org.cn (R.S.); panyamei@hnagri.org.cn (Y.P.); \\ wuchao@hnagri.org.cn (C.W.) \\ 2 Henan International Joint Laboratory of Crop Protection, Henan Biopesticide Engineering Research Center, \\ Henan Academy of Agricultural Sciences, Zhengzhou 450002, China \\ 3 Department of Plant Pathology, College of Plant Protection, Henan Agricultural University, \\ Zhengzhou 450002, China; xulingling@hnagri.org.cn \\ 4 School of Environmental Sciences, University of Guelph, Guelph, ON N1G2W1, Canada; \\ pgoodwin@uoguelph.ca \\ 5 Department of Plant Pathology, College of Plant Protection, China Agricultural University, \\ Beijing 100083, China; wangqi@cau.edu.cn \\ * Correspondence: yanglirong@hnagri.org.cn
}

check for updates

Citation: Xu, W.; Xu, L.; Deng, X.; Goodwin, P.H.; Xia, M.; Zhang, J.; Wang, Q.; Sun, R.; Pan, Y.; Wu, C.; et al. Biological Control of Take-All and Growth Promotion in Wheat by Pseudomonas chlororaphis YB-10. Pathogens 2021, 10, 903. https:// doi.org/10.3390/pathogens10070903

Academic Editors: Huijun $\mathrm{Wu}$ and Xuewen Gao

Received: 11 May 2021

Accepted: 13 July 2021

Published: 17 July 2021

Publisher's Note: MDPI stays neutral with regard to jurisdictional claims in published maps and institutional affiliations.

Copyright: (c) 2021 by the authors. Licensee MDPI, Basel, Switzerland. This article is an open access article distributed under the terms and conditions of the Creative Commons Attribution (CC BY) license (https:/ / creativecommons.org/licenses/by/ $4.0 /)$.

\begin{abstract}
Wheat is a worldwide staple food crop, and take-all caused by Gaeumannomyces graminis var. tritici can lead to a tremendous decrease in wheat yield and quality. In this study, strain YB-10 was isolated from wheat rhizospheric soil and identified as Pseudomonas chlororaphis by morphology and 16S rRNA gene sequencing. Pseudomonas chlororaphis YB-10 had extracellular protease and cellulase activities and strongly inhibited the mycelium growth of Gaeumannomyces graminis var. tritici in dual cultures. Up to 87\% efficacy of Pseudomonas chlororaphis YB-10 in controlling the take-all of seedlings was observed in pot experiments when wheat seed was coated with the bacterium. Pseudomonas chlororaphis YB-10 was also positive for indole acetic acid (IAA) and siderophore production, and coating wheat seed with the bacterium significantly promoted the growth of seedlings at $10^{7}$ and $10^{8} \mathrm{CFU} / \mathrm{mL}$. Furthermore, treatment with Pseudomonas chlororaphis YB-10 increased activities of the wheat defense-related enzymes POD, SOD, CAT, PAL and PPO in seedlings, indicating induced resistance against pathogens. Overall, Pseudomonas chlororaphis YB-10 is a promising new seed-coating agent to both promote wheat growth and suppress take-all.
\end{abstract}

Keywords: take-all; biocontrol; growth-promoting; Pseudomonas chlororaphis; Gaeumannomyces graminis var. tritici

\section{Introduction}

Take-all caused by Gaeumannomyces graminis var. tritici $(G g t)$ is one of the most destructive root diseases of wheat worldwide and significantly reduces wheat grain yield after severe outbreaks [1-3]. The fungus G. graminis var. tritici damages wheat by rotting the root and base of the stem, disrupting the uptake and flow of water and nutrients, and eventually causing death of infected plants $[2,4,5]$. As with other soil-borne plant diseases, take-all is difficult to manage by current approaches such as the development of resistant cultivars, use of chemical pesticides, crop rotation and tillage [6-10]. However, several studies in the past thirty years have demonstrated that antagonistic bacteria and fungi can be applied to wheat to control take-all disease. This is considered to be a more efficient and ecologically friendly alternative management approach [4,11-14]. Therefore, the identification of effective antagonistic microorganisms to control take-all disease in wheat is an urgent need for sustainable wheat production. 
Many studies have revealed that antagonistic bacteria not only play significant roles in controlling different plant diseases as biological control agents (BCAs), but can also increase plant growth as plant growth-promoting rhizobacteria (PGPR) [15-19]. Among them, isolates of Pseudomonas have proven to be capable of producing antibiotic compounds to suppress plant pathogens such as G. graminis var. tritici, and possess plant growth-promoting characteristics such as phosphate solubilization, siderophores, 1-aminocyclopropane-1carboxylate (ACC) deaminase and indole-3-acetic acid (IAA), etc. [20-24]. For example, $P$. chlororaphis 30-84 produced the antibiotic sphenazine-1-carboxylic acid (PCA) that effectively inhibited take-all [23]; P. fluorescens 2-79 also produced the antibiotics PCA that strongly inhibited G. graminis var. tritici in culture [25]; and P. fluorescens VUPf5 produced siderophores, hydrogen cyanide, protease, phenazine and volatile metabolites that suppressed take-all disease by $85 \%$ in pots [26]. Furthermore, isolates of Pseudomonas have been shown to be both BCAs and PGPRs in other plants. For example, P. aeruginosa 2apa produced IAA, salicylic acid and siderophores, and promoted tomato growth along with antimicrobial activity against a wide range of pathogens [27]. Pseudomonas aeruginosa PN1 produced IAA, cyanogens, solubilized phosphorus, siderophore, chitinase and $\beta-1$, 3-glucanase and improved the growth of chirpine seedlings along with exhibiting a strong antagonistic property against Macrophomina phaseolina [17]. In addition, inoculations with different Pseudomonas strains have triggered defense-related enzymes in plants, such as peroxidase (POD), superoxide dismutase (SOD), catalase (CAT), phenylalanine ammonia lyase (PAL) and polyphenoloxidase (PPO), indicating that they can produce induced systemic resistance against pathogens [28-32].

In this study, strain YB-10 was isolated from wheat rhizospheric soil and identified as Pseudomonas chlororaphis by morphology and 16S rRNA gene sequencing. It exhibited strong antagonistic activity against G. graminis var. tritici in dual cultures and was shown to have a number of potential growth-promoting and biocontrol traits. When used to coat wheat seeds, $P$. chlororaphis YB-10 not only promoted the growth of wheat seedlings, but also suppressed take-all caused by G. graminis var. tritici. These results demonstrated that P. chlororaphis YB-10 could be a promising BCA of wheat and PGPR against take-all disease.

\section{Materials and Methods}

\subsection{Isolation of Strain YB-10}

Soil sample collection and isolation of strain YB-10 from wheat rhizosphere used in this study were as previously described in [12].

\subsection{Identification of Strain $Y B-10$}

A single colony of strain YB-10 was inoculated in Nutrient Broth and grown for $24 \mathrm{~h}$ at $30{ }^{\circ} \mathrm{C}$, shaking at $150 \mathrm{rpm}$. Genomic DNA of YB-10 was extracted by the MiniBEST Bacterial Genomic DNA Extraction Kit Ver. 3.0 (TaKaRa, Beijing, China) following the manufacturer's instructions. The $16 \mathrm{~S}$ rRNA gene fragment was amplified with primers27F (5'-AGAGTTTGATCCTGGCTCAG-3') and 1492R (5'-GGTTACCTTGTTACGACTT-3'). A phylogenetic tree of the 16S rRNA gene sequences was constructed with MEGA 7.0 using the neighbor joining method [33].

\subsection{Detection of PGP and Antifungal Traits}

IAA production was detected with the Salkowski method as described by Glickmann and Dessaux [34].

Siderophore production was determined on Chrome Azurol S blue agar (CAS) [35]. A single colony of $P$. chlororaphis YB-10 was inoculated on CAS and cultured at $30^{\circ} \mathrm{C}$ in the dark. Siderophore production was indicated by the color change from blue to orange around the colonies.

A single colony of $P$. chlororaphis YB-10 was inoculated onto carboxymethylcellulose agar and incubated for 7 days at $30{ }^{\circ} \mathrm{C}$. The plates were flooded with $1 \%(\mathrm{~m} / \mathrm{v})$ Congo red 
and then washed with distilled water. The cellulose activity was detected as clear zones around the colonies [36].

Protease activity was detected on skim milk agar $\left(5 \mathrm{~g} \mathrm{NaCl}, 0.1 \mathrm{~g} \mathrm{CaCl}_{2}, 10 \mathrm{~g}\right.$ peptone, $10 \mathrm{~g}$ skim milk and $18 \mathrm{~g}$ of agar per liter ( $\mathrm{pH} 7.2)$ ). A single colony of $P$. chlororaphis YB-10 was placed on the medium and incubated at $30{ }^{\circ} \mathrm{C}$ for 5 days. Protease activity of P. chlororaphis YB-10 was observed by the clear zones around the colonies [37].

\subsection{Plant Growth Promotion Assay of P. chlororaphis YB-10 on Wheat Seedlings}

P. chlororaphis YB-10 was cultured in $100 \mathrm{~mL} \mathrm{NB}$ broth for $36 \mathrm{~h}$ at $30^{\circ} \mathrm{C}$ with shaking at $180 \mathrm{rpm}$. Wheat (Triticum aestivum L.) seeds of cultivar Zhengmai 366 were surfacesterilized in $75 \%$ ethanol $(v / v)$ for 30 s and then rinsed with sterile water three times. Wheat seeds were air-dried and then soaked with a suspension of $P$. chlororaphis YB-10 at $10^{7} \mathrm{CFU} / \mathrm{mL}, 10^{8} \mathrm{CFU} / \mathrm{mL}$ or $10^{9} \mathrm{CFU} / \mathrm{mL}$ for $2 \mathrm{~h}$. The seeds were then placed in a Petri dish with a diameter of $9 \mathrm{~cm}$ in the greenhouse at $25^{\circ} \mathrm{C}$ with a $12 \mathrm{~h}$ light/12 $\mathrm{h}$ dark photoperiod for 10 days. Each treatment had three replicates. Seeds soaked with NB medium were used as control.

\subsection{Biocontrol Assay of P. chlororaphis YB-10 Against Take-All inWheat}

Wheat seeds were soaked with $P$. chlororaphis YB-10 at $10^{7} \sim 10^{8} \mathrm{CFU} / \mathrm{mL}$ or sterile NB medium as described above. The seeds were air-dried, and 15 seeds were planted per pot $(10 \mathrm{~cm}$ high, $10 \mathrm{~cm}$ diameter) filled with $350 \mathrm{~g}$ potting soil. The pots were placed in the greenhouse at $25^{\circ} \mathrm{C}$. Gaeumannomyces graminis var. tritici GGT-007, isolated from Xiping, Henan Province in 2014, that was previously shown to be highly virulent to wheat (data not shown), was grown on PDA for 10 days at $25^{\circ} \mathrm{C}$. A $5 \mathrm{~mm}$ disc of mycelium with agar from the growing edge of the colony was placed at a $1 \mathrm{~cm}$ depth in a pot and then a wheat seed was attached to the surface of the mycelial disc. This method of inoculation was shown to achieve a $100 \%$ infection rate [12]. Four treatments were made:

1. Seeds soaked with P. chlororaphis YB-10 and not inoculated with Ggt;

2. Seeds soaked with P. chlororaphis YB-10 and inoculated with Ggt;

3. Seeds not soaked with P. chlororaphis YB-10 and not inoculated with Ggt;

4. Seeds not soaked with P. chlororaphis YB-10 and inoculated with Ggt.

At 3 weeks post-planting, the treated wheat seedlings were removed from pots and roots were washed free of soil. The symptoms of take-all, disease index and control efficacy were measured as per Yang et al [12]. The experiment was replicated three times.

\subsection{Activities of Defense Enzymes in Wheat Seedlings}

At 3 weeks post-planting, the shoots of the treated wheat seedlings were harvested and stored at $-80{ }^{\circ} \mathrm{C}$. In brief, $0.5 \mathrm{~g}$ shoots were ground in liquid nitrogen, and a $1 \mathrm{~mL}$ extraction buffer was added. The buffer was then centrifuged, and the supernatant was removed and used for enzyme assays. The activities of SOD, POD, CAT, PAL and PPO were measured following the procedures of the manufacturer (Solarbio, Beijing, China) using an SOD assay kit (Cat. No. BC0175), POD assay kit (Cat. No. BC0095), CAT assay kit (Cat. No. BC0205), PAL assay kit (Cat. No. BC0215) and PPO assay kit (Cat. No. BC0195), respectively. Absorbance was determined by a plate reader (Tecan Spark, Tecan, Switzerland).

\subsection{Statistical Analysis}

Statistical analysis was performed using SPSS v21.0, one-way analysis of variance (ANOVA). Means were compared with Duncan's multiple range tests at a probability of $p \leq 0.05$. 


\section{Results}

\subsection{Screening and Identification of Strain $Y B-10$}

Strain YB-10 isolated from wheat rhizospheric soil was milky-white, non-pigmented on NA and Gram-negative (Figure 1A,C). Dual cultures of strain YB-10 and G. graminis var. tritici on NA displayed strong growth inhibition of $G$. graminis var. tritici by $\mathrm{YB}$ 10 (Figure 1B). A search using the $16 \mathrm{~S}$ rDNA sequence of YB-10 with the Basic Local Alignment Search Tool (BLAST) against the NCBI nr database demonstrated that strain YB-10 had 100\% sequence homology to $P$. chlororaphis. The sequence data were submitted to GenBank with the accession number MW093066. The phylogenetic tree of the $16 \mathrm{~S}$ rRNA gene sequences revealed that strain YB-10 was in a cluster of P. chlororaphis isolates (Figure 2).
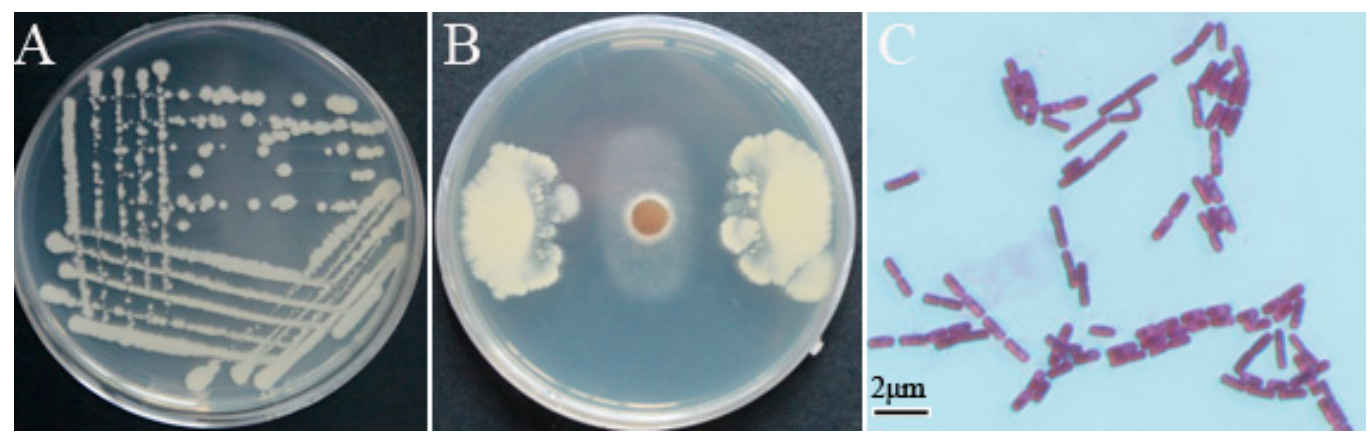

Figure 1. Characteristics of Pseudomonas chlororaphis YB-10. (A) Morphology of P. chlororaphis YB-10 on NA. (B) Inhibition of growth of G. graminis var. tritici by P. chlororaphis YB-10. (C) Gram staining of P. chlororaphis YB-10.

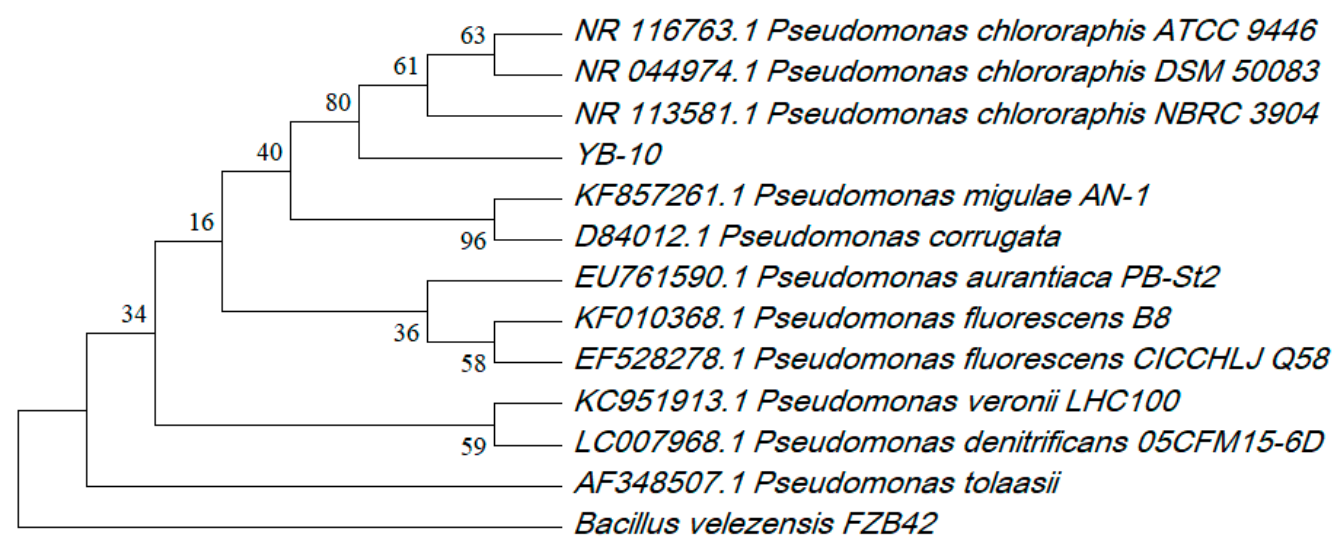

Figure 2. Phylogenetic tree of $P$. chlororaphis YB-10 and 12 other bacteria isolates based on $16 \mathrm{~S}$ rDNA sequences. Bootstrap values were from 1000 replicates.

\subsection{Characterization of In Vitro Antifungal and PGP Traits of P. chlororaphis YB-10}

P. chlororaphis YB-10 was capable of synthesizing indole acetic acid (IAA) (Figure 3A), producing siderophores (Figure $3 \mathrm{C}$ ), and secreting extracellular cellulase and protease (Figure 3B,D). However, P. chlororaphis YB-10 showed no phosphate solubilization or 1aminocyclopropane-1-carboxylic acid (ACC) deaminase activities (data not shown). 

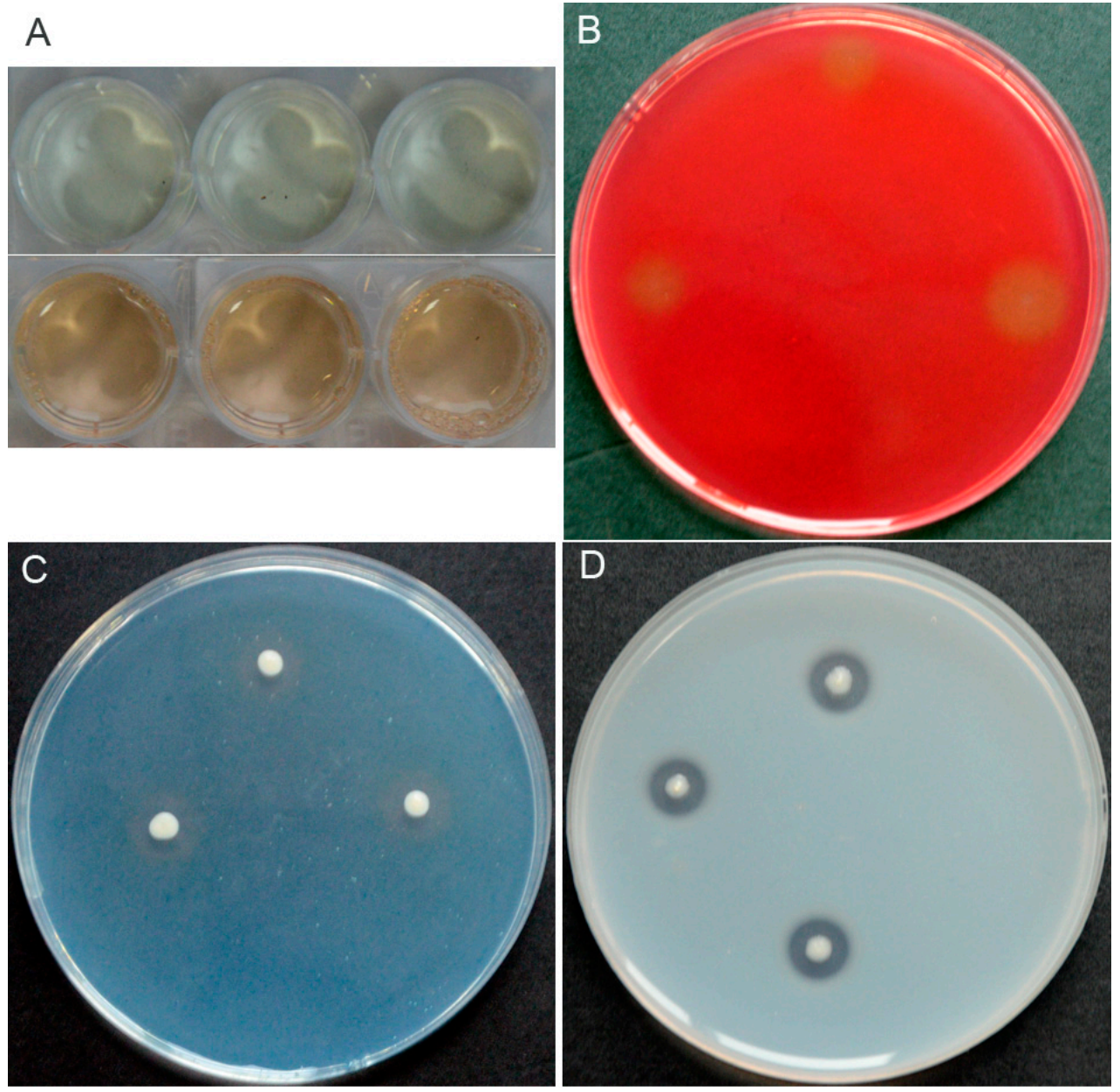

Figure 3. In vitro antifungal and PGP traits of $P$. chlororaphis YB-10. (A) Pink coloration indicating IAA production. (B) Clear zones indicating cellulase activity. (C) Orange halos indicating siderophore production. (D) Clear zones indicating protease activity.

\subsection{Effect of P. chlororaphis YB-10 Against Take-All in Wheat Seedlings}

For wheat seedlings at 21 days after G. graminis var. tritici inoculation without seed treatment of $P$. chlororaphis $\mathrm{YB}-10$ in pots under greenhouse conditions (Figure 4 ), symptoms of take-all, including blackened or chocolate brown lesions on the stembase and root, were observed (Figure 4D,H). Limited typical disease symptoms were observed in wheat seedlings without G. graminis var. tritici inoculation and without seed treatment of P. chlororaphis YB-10, indicating a low level of G. graminis var. tritici in the potting soil (Figure 4C,G). However, no typical disease symptoms were observed with or without G. graminis var. tritici inoculation with wheat seed treatment of $P$. chlororaphis YB-10 (Figure 4A,E,B,F, respectively). The disease index of wheat seedlings was $7.14 \pm 0.11$ and $6.67 \pm 0.28$ with seed treatment of P. chlororaphis YB-10 without or with G. graminis var. tritici inoculation, respectively, but the disease index was $78.57 \pm 0.47$ and $51.59 \pm 1.11$ without seed treatment of P. chlororaphis YB-10 with or without G. graminis var. tritici inoculation, respectively (Table 1). Disease incidence with seed treatment of $P$. chlororaphis YB-10 with or without G. graminis var. tritici inoculation was only $0.07 \%$. However, disease incidence was $92.86 \% \pm 0.62 \%$ and $64.29 \% \pm 0.72 \%$ without seed treatment of $P$. chlororaphis YB-10 with or without G. graminis var. tritici inoculation, respectively. The take-all control efficacy in wheat seedlings was $86-87 \%$ with seed treatment of P. chlororaphis YB-10. 


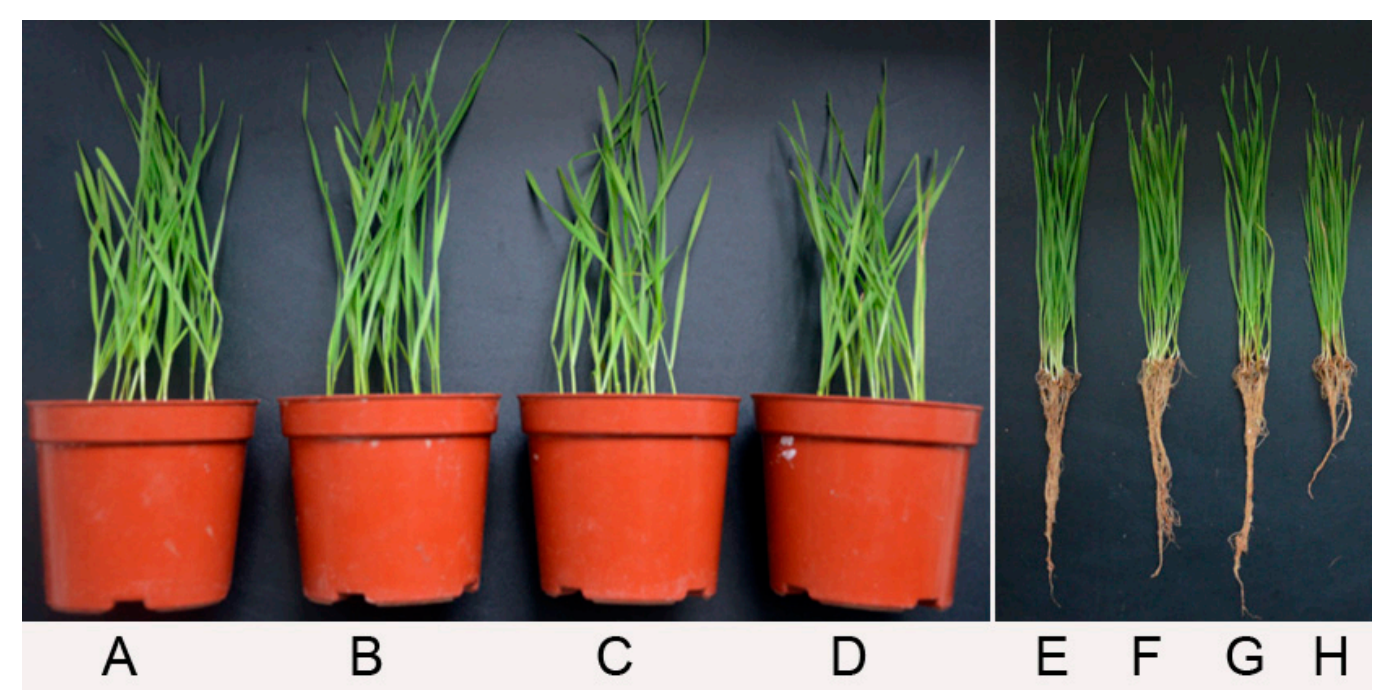

Figure 4. Effect of $P$. chlororaphis YB-10 against take-all in wheat seedlings. (A,E) Wheat seeds treatments of $P$. chlororaphis YB-10 without G. graminis var. tritici inoculation. (B,F) Wheat seeds treatments of P. chlororaphis YB-10 with G. graminis var. tritici inoculation. (C,G) Control treatments without G. graminis var. tritici inoculation. (D,H) Control treatments with G. graminis var. tritici inoculation.

Table 1. Disease incidence, disease index and control efficacy of $P$. chlororaphis YB-10 against take-all of wheat.

\begin{tabular}{cccc}
\hline Treatment & Disease Incidence (\%) & Disease Index & Control Efficacy (\%) \\
\hline CK & $64.29 \pm 0.72^{\mathrm{b}}$ & $51.59 \pm 1.11^{\mathrm{b}}$ & $87.07 \pm 0.54^{\mathrm{a}}$ \\
YB-10 & $0.07 \pm 0.00^{\mathrm{c}}$ & $6.67 \pm 0.28^{\mathrm{c}}$ & \\
Ggt inoculation & $92.86 \pm 0.62^{\mathrm{a}}$ & $78.57 \pm 0.47^{\mathrm{a}}$ & $86.16 \pm 2.23^{\mathrm{a}}$ \\
\hline
\end{tabular}

Note: data are the Mean \pm Standard deviation (SD); Different letters (a-c) in the same column indicate significant difference at $p$ values $<0.05$ level.

\subsection{Growth Promotion of Wheat Seedlings after P. chlororaphis YB-10 Inoculation}

For wheat seeds soaked with P. chlororaphis YB-10 at different doses, P. chlororaphis YB-10 at $10^{7}$ and $10^{8} \mathrm{CFU} / \mathrm{mL}$ significantly promoted the growth of wheat seedlings, but $P$. chlororaphis YB- 10 at $10^{9} \mathrm{CFU} / \mathrm{mL}$ had an inhibitory effect on the growth of wheat seedlings (Figure 5). The fresh weights of shoots of wheat seedlings inoculated with P. chlororaphis YB-10 at $10^{7}$ and $10^{8} \mathrm{CFU} / \mathrm{mL}$ were $1.68 \pm 0.06 \mathrm{~g}$ and $1.72 \pm 0.04 \mathrm{~g}$, respectively, compared to $1.18 \pm 0.07 \mathrm{~g}$ without inoculation with $P$. chlororaphis $\mathrm{YB}-10$. The fresh weights of roots of wheat seedlings inoculated with P. chlororaphis YB-10 at $10^{7}$ and $10^{8} \mathrm{CFU} / \mathrm{mL}$ were $1.53 \pm 0.03 \mathrm{~g}$ and $1.51 \pm 0.05 \mathrm{~g}$, respectively, compared to $0.91 \pm 0.02 \mathrm{~g}$ without inoculation with P. chlororaphis YB-10. The lengths of shoots of wheat seedlings inoculated with $P$. chlororaphis YB-10 at $10^{7}$ and $10^{8} \mathrm{CFU} / \mathrm{mL}$ were $12.41 \pm 0.52 \mathrm{~cm}$ and $12.43 \pm 0.67 \mathrm{~cm}$, respectively, compared to $8.21 \pm 0.42 \mathrm{~cm}$ without inoculation with P. chlororaphis YB-10. Overall, seed treatment with P. chlororaphis $\mathrm{YB}-10$ at $10^{7}$ and $10^{8}$ $\mathrm{CFU} / \mathrm{mL}$ caused a significant improvement $(p<0.05)$ in fresh weights of shoots and roots and in the lengths of shoots of wheat seedlings, but seed treatment with $P$. chlororaphis YB-10 at $10^{9} \mathrm{CFU} / \mathrm{mL}$ did not differ significantly $(p>0.05)$ compared with non-inoculated treatment (Table 2). 


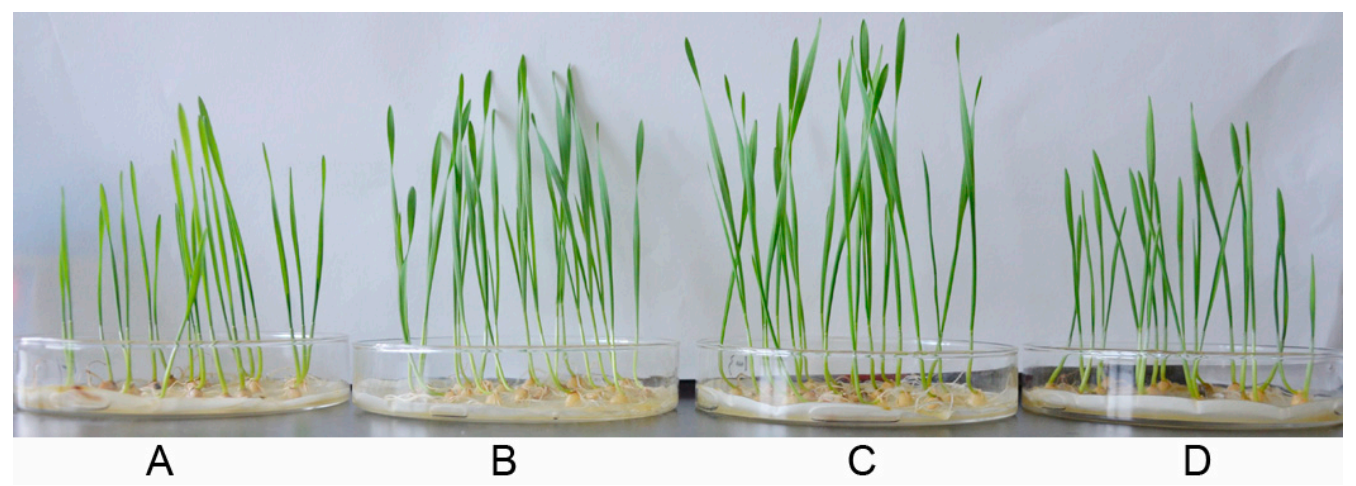

Figure 5. Growth promotion of wheat seedlings by P. chlororaphis YB-10. (A) Wheat seeds soaked without P. chlororaphis YB-10. (B) Wheat seeds soaked with P. chlororaphis YB-10 at $10^{7} \mathrm{CFU} / \mathrm{mL}$. (C) Wheat seeds soaked with P. chlororaphis YB-10 at $10^{8} \mathrm{CFU} / \mathrm{mL}$. (D) Wheat seeds soaked with P. chlororaphis YB-10 at $10^{9} \mathrm{CFU} / \mathrm{mL}$.

Table 2. Root and shoot fresh weights and shoot lengths of wheat seedlings by P. chlororaphis YB-10.

\begin{tabular}{cccc}
\hline Treatment & Root Fresh Weight (g) & Shoot Fresh Weight (g) & Shoot Length (cm) \\
\hline CK & $0.91 \pm 0.02^{\mathrm{b}}$ & $1.18 \pm 0.07^{\mathrm{b}}$ & $8.21 \pm 0.42^{\mathrm{b}}$ \\
$\mathrm{YB}-10\left(10^{9} \mathrm{CFU} / \mathrm{mL}\right)$ & $0.89 \pm 0.03^{\mathrm{b}}$ & $1.17 \pm 0.01^{\mathrm{b}}$ & $8.255 \pm 0.37^{\mathrm{b}}$ \\
$\mathrm{YB}-10\left(10^{8} \mathrm{CFU} / \mathrm{mL}\right)$ & $1.51 \pm 0.05^{\mathrm{a}}$ & $1.72 \pm 0.04^{\mathrm{a}}$ & $12.43 \pm 0.67^{\mathrm{a}}$ \\
$\mathrm{YB}-10\left(10^{7} \mathrm{CFU} / \mathrm{mL}\right)$ & $1.53 \pm 0.03^{\mathrm{a}}$ & $1.68 \pm 0.06^{\mathrm{a}}$ & $12.41 \pm 0.52^{\mathrm{a}}$ \\
\hline
\end{tabular}

Note: data are Mean \pm SD; Different letters $(a, b)$ in the same column indicate significant difference at $p$ values $<0.05$ level.

\subsection{Effect of P. chlororaphis YB-10 on Activities of Defense Enzymes in Wheat Seedlings}

POD activity of wheat shoots was $9406.51 \pm 200.20 \mathrm{U} / \mathrm{g}$ and 12,925.14 $\pm 998.21 \mathrm{U} / \mathrm{g}$ with seed treatment of P. chlororaphis YB-10 without or with G. graminis var. tritici inoculation, respectively, whereas the POD activity was 7261.47 $\pm 251.01 \mathrm{U} / \mathrm{g}$ and 10,517.07 $\pm 234.12 \mathrm{U} / \mathrm{g}$ without seed treatment of $P$. chlororaphis YB-10 without or with G. graminis var. tritici inoculation, respectively (Figure 6). PPO activity of wheat shoots was $85.46 \pm 6.16 \mathrm{U} / \mathrm{g}$ and $166.95 \pm 4.87 \mathrm{U} / \mathrm{g}$ with seed treatment of $P$. chlororaphis YB-10 without or with G. graminis var. tritici inoculation, respectively, whereas PPO activity was $70.16 \pm 5.18 \mathrm{U} / \mathrm{g}$ and $128.78 \pm 5.67 \mathrm{U} / \mathrm{g}$ without seed treatment of $P$. chlororaphis YB-10 without or with G. graminis var. tritici inoculation, respectively. CAT activity of wheat shoots was $201.73 \pm 7.18 \mathrm{U} / \mathrm{g}$ and $387.59 \pm 10.94 \mathrm{U} / \mathrm{g}$ in seed treatment of $P$. chlororaphis YB-10 without or with G. graminis var. tritici inoculation, respectively, whereas CAT activity was $161.97 \pm 7.40 \mathrm{U} / \mathrm{g}$ and $241.73 \pm 5.76 \mathrm{U} / \mathrm{g}$ without seed treatment of P. chlororaphis YB-10 without or with G. graminis var. tritici inoculation, respectively. PAL activity of wheat shoots was $39.78 \pm 3.46 \mathrm{U} / \mathrm{g}$ and $57.38 \pm 4.11 \mathrm{U} / \mathrm{g}$ with seed treatment of P. chlororaphis YB-10 without or with G. graminis var. tritici inoculation, respectively, whereas PAL activity was $30.87 \pm 2.33 \mathrm{U} / \mathrm{g}$ and $45.61 \pm 2.47 \mathrm{U} / \mathrm{g}$ without seed treatment of $P$. chlororaphis YB-10 without or with G. graminis var. tritici inoculation, respectively. SOD activity of wheat shoots was $881.57 \pm 25.97 \mathrm{U} / \mathrm{g}$ and $1514.12 \pm 54.61 \mathrm{U} / \mathrm{g}$ with seed treatment of $P$. chlororaphis YB-10 without or with G. graminis var. tritici inoculation, respectively, whereas SOD activity was $748.87 \pm 16.23 \mathrm{U} / \mathrm{g}$ and $1178.64 \pm 62.32 \mathrm{U} / \mathrm{g}$ without seed treatment of $P$. chlororaphis YB-10 without or with G. graminis var. tritici inoculation, respectively. In general, wheat seeds soaked with $P$. chlororaphis YB-10 resulted in significant increases in POD, SOD, CAT, PAL and PPO activities of wheat shoots regardless of G. graminis var. tritici inoculation. 


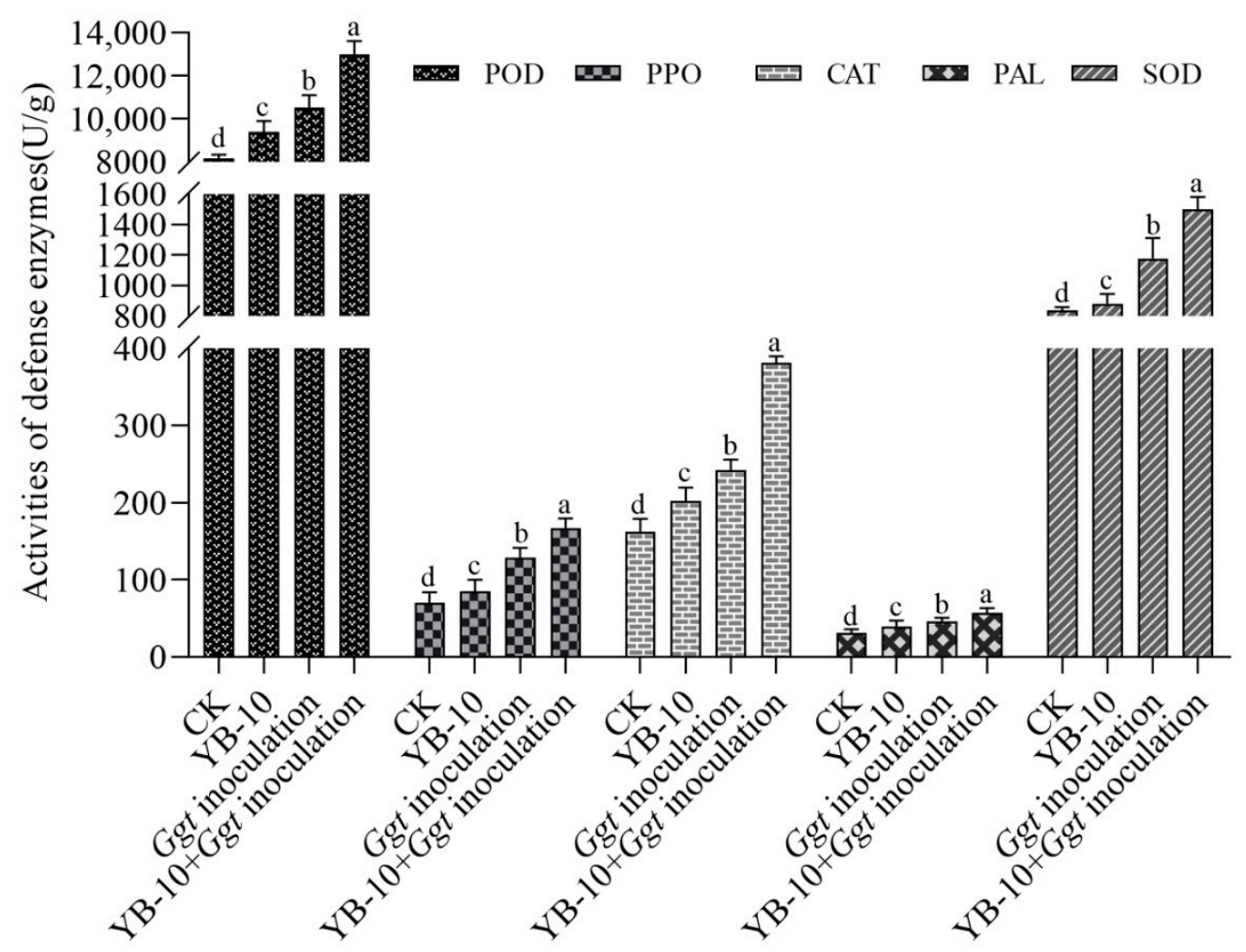

Figure 6. Five defense enzymes activities of wheat shoots under different treatments. peroxidase (POD), superoxide dismutase (SOD), catalase (CAT), phenylalanine ammonia lyase (PAL) and polyphenoloxidase (PPO). Data are mean \pm standard deviation (SD) of three replicates; Different letters $(a-d)$ in the same enzyme indicate significant difference at $p$ values $<0.05$ level.

\section{Discussion}

In recent years, many studies have demonstrated that $P$ seudomonas strains from the plant rhizosphere could control diseases caused by a variety of pathogens [21,38-40]. For example, Pseudomonas fluorescens CV6 had broad antimicrobial activity against 12 pathogens [41], and P. fluorescens VUPf5 strongly inhibited G. graminis var. tritici in vitro and greenhouse, suppressing take-all disease by $85 \%$ [26]. Many of these strains have antifungal attributes, such as $\beta$-1,3-glucanase, cellulase, protease and chitinase activities [42,43]. It is also well known that a number of Pseudomonas strains from the plant rhizosphere can promote plant growth $[18,20,40,41]$. These strains show multiple growth-promoting properties, including IAA production, siderophore production, hydrogen cyanide production and phosphate solubilization [42,43]. Further screening of new Pseudomonas isolates is desirable for creating new options for controlling plant diseases and promoting plant growth in sustainable agriculture systems.

In this study, P. chlororaphis strain YB-10 was isolated from wheat rhizosphere, which had cellulose and protease activities and suppressed take-all caused by G. graminis var. tritici with very high efficacy. In addition, $P$. chlororaphis $\mathrm{YB}-10$ was positive for IAA and siderophore production and significantly promoted the growth of wheat seedlings at $10^{7}$ and $10^{8} \mathrm{CFU} / \mathrm{mL}$. However, the growth promotion effect was dose-dependent as wheat seedlings soaked with $P$. chlororaphis YB- 10 at $10^{9} \mathrm{CFU} / \mathrm{mL}$ did not differ significantly compared with non-inoculated treatment. Therefore, $P$. chlororaphis YB-10 showed itself to be an effective PGPR for wheat seedlings and BCA against take-all of wheat.

In nature, plants are attacked by various pathogens inducing the production of different defense-related enzymes that play important roles in disease resistance [44,45]. The level of defense-related enzymes, such as POD, PPO, CAT, PAL and SOD, have been correlated with plant disease resistance $[46,47]$. Many studies have reported that biocontrol agents such as P. fluorescens, Pseudomonas sp. 23S, Bacillus subtilis, P. chlororaphis ToZa7 and Clonostachys rosea IK726 induced the expression of defense-related enzymes including SOD, 
CAT, PAL and PPO $[24,31,46,48,49]$. In this study, the activities of POD, PPO, CAT, PAL and SOD were increased significantly with seed treatment of $P$. chlororaphis YB-10 in healthy plants (i.e., without $G$. graminis var. tritici inoculation); activities were also increased with G. graminis var. tritici inoculation alone, indicating that the enzymes can be induced by the bacterium or pathogen alone. However, the highest levels detected were with seed treatment of P. chlororaphis YB-10 with G. graminis var. tritici inoculation, indicating increased levels of induction compared to those caused by G. graminis var. tritici infection. However, the promotion of plant growth by P. chlororaphis YB-10 indicates that there are multiple effects on the plants, and some of those other effects could have contributed to controlling take-all disease.

In summary, this is the first report that the wheat rhizosphere bacterium, P. chlororaphis, can both promote wheat growth and control take-all disease. Strain YB-10 was positive for IAA and siderophore production and had extracellular protease and cellulase activities, all of which could contribute to its beneficial effects. Moreover, seed treatment with P. chlororaphis YB-10 could later increase activities of defense-related enzymes in shoots. This indicates that the control of take-all by P. chlororaphis YB-10 could be related to induced systemic resistance (ISR) in the wheat seedlings. ISR has previously been shown to occur during the control of wheat take-all using treatments with other rhizobacterial species, and it is believed that ISR is the main mechanism for their ability to suppress take-all disease [50].

Author Contributions: Conceptualization, L.Y. and Q.W.; methodology, L.X., X.D.; software, W.X., X.D.; validation, J.Z., M.X. and R.S.; formal analysis, W.X.; investigation, Y.P.; resources, C.W.; data curation, W.X.; writing-original draft preparation, W.X.; writing—review and editing, P.H.G., Q.W. and L.Y.; visualization, W.X.; project administration, L.Y.; funding acquisition, L.Y., W.X. and M.X.; All authors have read and agreed to the published version of the manuscript.

Funding: This research was funded by the Science-Technology Foundation for Outstanding Young Scientists of Henan Academy of Agricultural Sciences (2018YQ16), Major Achievement Cultivation Program of Henan Academy of Agricultural Sciences (20191101004), Independent Innovation Special Fund of Henan Academy of Agricultural Sciences (2020ZC31 and 2020ZC56), The Central Government Guiding Local Projects (2020 [44]).

Institutional Review Board Statement: Not applicable.

Informed Consent Statement: Not applicable.

Data Availability Statement: Not applicable.

Conflicts of Interest: All the authors declare that there was no potential conflict of commercial or financial interests.

\section{References}

1. Kwak, Y.S.; Weller, D.M. Take-all of Wheat and Natural Disease Suppression: A Review. Plant Pathol. J. 2013, 29, 125-135. [CrossRef]

2. James, C.R. Take-all of wheat. Physiol. Mol. Plant Pathol. 2003, 62, 73-86. [CrossRef]

3. Zhang, J.; Yan, H.; Xia, M.; Han, X.; Xie, L.; Goodwin, P.H.; Quan, X.; Sun, R.; Wu, C.; Yang, L. Wheat root transcriptional responses against Gaeumannomycesgraminis var. tritici. Phytopathol. Res. 2020, 2, 1-14.

4. Gholami, M.; Amini, J.; Abdollahzadeh, J.; Ashengroph, M. Basidiomycetes fungi as biocontrol agents against take-all disease of wheat. Biol. Control 2019, 130, 34-43. [CrossRef]

5. Yang, L.; Han, X.; Zhang, F.; Goodwin, P.H.; Yang, Y.; Li, J.; Xia, M.; Sun, R.; Jia, B.; Zhang, J.; et al. Screening Bacillus species as biological control agents of Gaeumannomycesgraminis var. Tritici on wheat. Biol. Control 2018, 118, 1-9. [CrossRef]

6. Bateman, G.L. Prospects for fungicidal control of take-all of wheat. Ann. Appl. Biol. 2010, 96, 275-282. [CrossRef]

7. Nelson, R.; Wiesner-Hanks, T.; Wisser, R.; Balint-Kurti, P. Navigating complexity to breed disease-resistant crops. Nat. Rev. Genet. 2018, 19, 21-33. [CrossRef] [PubMed]

8. Woźniak, A.; Soroka, M. Effect of crop rotation and tillage system on the weed infestation and yield of spring wheat and on soil properties. Appl. Ecol. Environ. Res. 2018, 16, 3087-3096. [CrossRef]

9. Rothrock, C.S. Take-all of wheat as affected by tillage and wheat-soybean doublecropping. Soil Biol. Biochem. 1987, 19, 307-311. [CrossRef] 
10. Bateman, G.L. Progress in research on the control of take-all in cereals with fungicides: A review. Crop. Prot. 1989, 8, 75-81. [CrossRef]

11. Maplestone, P.A.; Campbell, R. Colonization of roots of wheat seedlings by bacilli proposed as biocontrol agents against take-all. Soil Biol. Biochem. 1989, 21, 543-550. [CrossRef]

12. Yang, L.; Quan, X.; Xue, B.; Goodwin, P.H.; Lu, S.; Wang, J.; Du, W.; Wu, C. Isolation and identification of Bacillus subtilis strain YB-05 and its antifungal substances showing antagonism against Gaeumannomycesgraminis var. tritici. Biol. Control 2015, 85, 52-58. [CrossRef]

13. Liu, B.; Qiao, H.; Huang, L.; Buchenauer, H.; Han, Q.; Kang, Z.; Gong, Y. Biological control of take-all in wheat by endophytic Bacillus subtilis E1R-j and potential mode of action. Biol. Control 2009, 49, 277-285. [CrossRef]

14. Huang, Z.; Bonsall, R.F.; Mavrodi, D.V.; Weller, D.M.; Thomashow, L.S. Transformation of Pseudomonas fluorescens with genes for biosynthesis of phenazine-1-carboxylic acid improves biocontrol of rhizoctonia root rot and in situ antibiotic production. FEMS Microbiol. Ecol. 2004, 49, 243-251. [CrossRef]

15. Liu, K.; McInroy, J.A.; Hu, C.H.; Kloepper, J.W. Mixtures of Plant-Growth-Promoting Rhizobacteria Enhance Biological Control of Multiple Plant Diseases and Plant-Growth Promotion in the Presence of Pathogens. Plant Dis. 2018, 102, 67-72. [CrossRef] [PubMed]

16. Hayat, R.; Ali, S.; Amara, U.; Khalid, R.; Ahmed, I. Soil beneficial bacteria and their role in plant growth promotion: A review. Ann. Microbiol. 2010, 60, 579-598. [CrossRef]

17. Singh, N.; Kumar, S.; Bajpai, V.K.; Dubey, R.C.; Maheshwari, D.K.; Kang, S.C. Biological control of Macrophominaphaseolina by chemotactic fluorescent Pseudomonas aeruginosa PN1 and its plant growth promotory activity in chir-pine. Crop. Prot. 2010, 29, 1142-1147. [CrossRef]

18. Hernández-León, R.; Rojas-Solís, D.; Contreras-Pérez, M.; del Carmen Orozco-Mosqueda, M. Characterization of the antifungal and plant growth-promoting effects of diffusible and volatile organic compounds produced by Pseudomonas fluorescens strains. Biol. Control 2015, 81, 83-92. [CrossRef]

19. Santoyo, G.; Orozco-Mosqueda, M.D.C.; Govindappa, M. Mechanisms of biocontrol and plant growth-promoting activity in soil bacterial species of Bacillus and Pseudomonas: A review. Biocontrol Sci. Technol. 2012, 22, 855-872. [CrossRef]

20. Panpatte, D.G.; Jhala, Y.K.; Shelat, H.N.; Vyas, R.V. Pseudomonas Fluorescens: A Promising Biocontrol Agent and PGPR for Sustainable Agriculture; Springer: New Delhi, India, 2016.

21. Agaras, B.C.; Noguera, F.; Anta, G.G.; Wall, L.G.; Valverde, C. Biocontrol potential index of pseudomonads, instead of their direct-growth promotion traits, is a predictor of seed inoculation effect on crop productivity under field conditions. Biol. Control 2020, 143, 104209. [CrossRef]

22. Jain, R.; Pandey, A. A phenazine-1-carboxylic acid producing polyextremophilic Pseudomonas chlororaphis (MCC2693) strain, isolated from mountain ecosystem, possesses biocontrol and plant growth promotion abilities. Microbiol. Res. 2016, 190, 63-71. [CrossRef]

23. Mazzola, M.; Fujimoto, D.K.; Thomashow, L.S.; Cook, R.J. Variation in Sensitivity of Gaeumannomycesgraminis to Antibiotics Produced by Fluorescent Pseudomonas spp. and Effect on Biological Control of Take-All of Wheat. Appl. Environ. Microbiol. 1995, 61, 2554-2559. [CrossRef] [PubMed]

24. Kamou, N.N.; Cazorla, F.; Kandylas, G.; Lagopodi, A.L. Induction of defense-related genes in tomato plants after treatments with the biocontrol agents Pseudomonas chlororaphis ToZa7 and Clonostachys rosea IK726. Arch. Microbiol. 2020, 202, 257-267. [CrossRef] [PubMed]

25. Thomashow, L.S.; Weller, D.M. Role of a phenazine antibiotic from Pseudomonas fluorescens in biological control of Gaeumannomycesgraminis var. tritici. J. Bacteriol. 1988, 170, 3499-3508. [CrossRef]

26. Lagzian, A.; Saberi Riseh, R.; Khodaygan, P.; Sedaghati, E.; Dashti, H. Introduced Pseudomonas fluorescens VUPf5 as an important biocontrol agent for controlling Gaeumannomycesgraminis var. tritici the causal agent of take-all disease in wheat. Arch. Phytopathol. Plant Prot. 2013, 46, 2104-2116. [CrossRef]

27. Hariprasad, P.; Chandrashekar, S.; Singh, S.B.; Niranjana, S.R. Mechanisms of plant growth promotion and disease suppression by Pseudomonas aeruginosa strain 2apa. J. Basic Microbiol. 2014, 54, 792-801. [CrossRef] [PubMed]

28. Vanitha, S.C.; Umesha, S. Pseudomonas fluorescens mediated systemic resistance in tomato is driven through an elevated synthesis of defense enzymes. Biol. Plantarum 2011, 55, 317-322. [CrossRef]

29. Wang, M.; Zhao, L.; Zhang, X.; Dhanasekaran, S.; Abdelhai, M.H.; Yang, Q.; Jiang, Z.; Zhang, H. Study on biocontrol of postharvest decay of table grapes caused by Penicilliumrubens and the possible resistance mechanisms by Yarrowialipolytica. Biol. Control 2019, 130, 113-117. [CrossRef]

30. Li, Q.; Li, C.; Li, P.; Zhang, H.; Zhang, X.; Zheng, X.; Yang, Q.; Apaliya, M.T.; Boateng, N.A.S.; Sun, Y. The biocontrol effect of Sporidioboluspararoseus Y16 against postharvest diseases in table grapes caused by Aspergillus niger and the possible mechanisms involved. Biol. Control 2017, 113, 18-25. [CrossRef]

31. Li, S.M.; Hua, G.G.; Liu, H.X.; Guo, J.H. Analysis of defence enzymes induced by antagonistic bacterium Bacillus subtilis strain AR12 towards Ralstonia solanacearum in tomato. Ann. Microbiol. 2008, 58, 573-578. [CrossRef]

32. Qin, X.; Xiao, H.; Xue, C.; Yu, Z.; Yang, R.; Cai, Z.; Si, L. Biocontrol of gray mold in grapes with the yeast Hanseniasporauvarum alone and in combination with salicylic acid or sodium bicarbonate. Postharvest Biol. Technol. 2015, 100, 160-167. [CrossRef] 
33. Kumar, S.; Stecher, G.; Tamura, K. MEGA7: Molecular Evolutionary Genetics Analysis Version 7.0 for Bigger Datasets. Mol Biol. Evol. 2016, 33, 1870-1874. [CrossRef]

34. Glickmann, E.; Dessaux, Y. A critical examination of the specificity of the salkowski reagent for indolic compounds produced by phytopathogenic bacteria. Appl. Environ. Microbiol. 1995, 61, 793-796. [CrossRef] [PubMed]

35. Schwyn, B.; Neilands, J.B. Universal chemical assay for the detection and determination of siderophores. Anal. Biochem. 1987, 160, 47-56. [CrossRef]

36. Teather, R.M.; Wood, P.J. Use of Congo red-polysaccharide interactions in enumeration and characterization of cellulolytic bacteria from the bovine rumen. Appl. Environ. Microbiol. 1982, 43, 777-780. [CrossRef] [PubMed]

37. Kazanas, N. Proteolytic activity of microorganisms isolated from freshwater fish. Appl. Microbiol. 1968, 16, 128-132. [CrossRef] [PubMed]

38. Wahyudi, A.T.; Astuti, R.I. Screening of Pseudomonas sp. Isolated from Rhizosphere of Soybean Plant as Plant Growth Promoter and Biocontrol Agent. Am. J. Agric. Biol. Sci. 2011, 6, 134-141. [CrossRef]

39. Gopalakrishnan, S.; Upadhyaya, H.D.; Vadlamud, S. Plant growth-promoting traits of biocontrol potential bacteria isolated from rice rhizosphere. Springerplus 2012, 1, 1-7. [CrossRef]

40. David, B.V. Chapter 10- Pseudomonas fluorescens: A Plant-Growth-Promoting Rhizobacterium (PGPR) With Potential Role in Biocontrol of Pests of Crops. Crop. Improv. Through Microb. Biotechnol. 2018, 221-243. [CrossRef]

41. Maleki, M.; Mostafaee, S.; Mokhtarnejad, L.; Farzaneh, M. Characterization of'Pseudomonas fluorescens' Strain CV6 Isolated from Cucumber Rhizosphere in Varamin as a Potential Biocontrol Agent. Aust. J. Crop. Sci. 2010, 4, 676-683.

42. Gopalakrishnan, S.; Srinivas, V.; Prakash, B.; Sathya, A.; Vijayabharathi, R. Plant growth-promoting traits of Pseudomonas geniculata isolated from chickpea nodules. 3 Biotech 2015, 5, 653-661. [CrossRef] [PubMed]

43. Uzair, B.; Kausar, R.; Bano, S.A.; Fatima, S.; Badshah, M.; Habiba, U.; Fasim, F. Isolation and Molecular Characterization of a Model Antagonistic Pseudomonas aeruginosa Divulging In Vitro Plant Growth Promoting Characteristics. BioMed Res. Int. 2018, 2018, 6147380. [CrossRef]

44. Prasannath, K. Plant defense-related enzymes against pathogens: A review. AGRIEAST J. Agric. Sci. 2017, 11, 38. [CrossRef]

45. Zhao, Y.; Tu, K.; Shao, X.; Jing, W.; Su, Z. Effects of the yeast Pichia guilliermondii against Rhizopus nigricans on tomato fruit. Postharvest Biol. Technol. 2008, 49, 113-120. [CrossRef]

46. Anand, T.; Chandrasekaran, A.; Kuttalam, S.; Raguchander, T.; Prakasam, V.; Samiyappan, R. Association of some plant defense enzyme activities with systemic resistance to early leaf blight and leaf spot induced in tomato plants by azoxystrobin and Pseudomonas fluorescens. J. Plant Interact. 2007, 2, 233-244. [CrossRef]

47. Ethan, A.; Shaukat, A.; Emmanuel, B.; Yang, Y.; Madhav, N. Disease Resistance Mechanisms in Plants. Genes $2018,9,339$.

48. Chen, F.; Wang, M.; Zheng, Y.; Luo, J.; Yang, X.; Wang, X. Quantitative changes of plant defense enzymes and phytohormone in biocontrol of cucumber Fusarium wilt by Bacillus subtilis B579. World J. Microbiol. Biotechnol. 2010, 26, 675-684. [CrossRef]

49. Takishita, Y.; Charron, J.B.; Smith, D.L. Biocontrol Rhizobacterium Pseudomonassp. 23 S Induces Systemic Resistance in Tomato (Solanum lycopersicum L.) Against Bacterial Canker Clavibactermichiganensis subsp. michiganensis. Front. Microbiol. 2018, 9, 2119. [CrossRef]

50. Jasem, A.M.; Sharifi, R.; Abbasi, S. Induced systemic resistance to wheat take-all disease by probiotic bacteria. J. PlantProtection Res. 2018, 58, 304-310. 